\title{
EDUCAÇÃO FINANCEIRA: CONTEXTUALIZANDO E DIALOGANDO COM CONCEITOS MATEMÁTICOS NO ENSINO FUNDAMENTAL
}

\section{FINANCIAL EDUCATION CONTEXTUALIZING AND DIALOGUING WITH MATHEMATICAL CONCEPTS IN ELEMENTARY SCHOOL}

\author{
Wilma Pereira Santos Faria ${ }^{1}$ \\ Maria Teresa Menezes Freitas ${ }^{2}$
}

\begin{abstract}
Resumo: Este estudo trata de um relato de uma oficina sobre Educação Financeira que teve como objetivo aproximar os estudantes do ensino fundamental de conceitos financeiros a partir da contextualização, da reflexão de situações sugeridas e de organização orçamentaria. Buscou-se responder a seguinte questão: Quais são as possibilidades de aprendizagem sobre a Educação Financeira no $9^{\circ}$ ano do ensino fundamental no âmbito de uma oficina escolar? A luz da metodologia qualitativa buscou-se estudar as potencialidades das tarefas propostas na oficina. Os resultados observados apontam a contuibuição proveniente de reflexões a respeito de temas monetários com alunos do ensino fundamental.
\end{abstract}

Palavras-chave: Educação Financeira; Ensino Fundamental; Educação Matemática Critica.

Abstract: This study refers to the outcome of a Financial Education workshop with the objective of bringing the elementary school students closer to financial concepts from contextualization, reflection on suggested situations and budget organization. We sought to answer the following question: What are the possibilities for learning about Financial Education in the 9th year of elementary school within a school workshop? The study based on qualitative methodology and aimed to study the potential of the tasks of this workshop. The observed results point out how constructive it is to propose reflections on monetary issues for elementary school students

Keywords: Financial education; Elementary School; Critical Mathematics Education.

\section{Introdução}

Este artigo relata uma experiência de oficina de Educação Financeira, que se deu a partir das observações dos autores que apresentam a necessidade de se explorar conceitos e incentivar reflexões acerca dos assuntos monetários na Educação Básica. Trata-se de um recorte de um Trabalho de Conclusão de Curso.

Inicialmente apresenta-se um breve diálogo com a literatura sobre Educação Matemática Crítica (EMC) como uma possibilidade de fundamentação crítica e

\footnotetext{
${ }^{1}$ Licenciada em Matemática pela Universidade Federal de Uberlândia (UFU). Mestranda do Programa de Pós-Graduação em Ensino de Ciências e Matemática da Universidade Federal de Uberlândia (PPGECM/UFU), Uberlândia, MG, Brasil. E-mail: wilmasantosfaria@gmail.com

${ }^{2}$ Doutora em Educação Matemática pela Universidade Estadual de Campinas (UNICAMP). Professora do Programa de Pós-Graduação em Ensino de Ciências e Matemática da Universidade Federal de Uberlândia (PPGECM/UFU), Uberlândia, MG, Brasil. E-mail: $\underline{\text { mtmfreitas @gmail.com }}$
} 


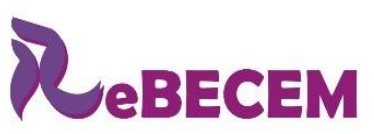

Revista Brasileira de Educação em

Ciências e Educação Matemática

ISSN 2594-9179

DOI: http://dx.doi.org/10.33238/ReBECEM.2019.v.3.n.2.22637

democrática para à Educação Financeira (EF). Tomando como referência, Ole Skovsmose, especialmente em seu livro intitulado Educação Matemática Crítica: a questão da democracia, destaca-se a defesa do autor ao afirmar que "A educação tem de desempenhar um papel ativo na identificação e no combate de disparidades sociais" (SKOVSMOSE, 2001, p.32). Levando em conta a necessidade de combater a disparidade social planejou-se a oficina considerando a bibliografia que aborda aspectos da Educação Matemática neste contexto. A oficina foi oferecida à alunos do $9^{\circ}$ ano do ensino fundamental, com encontros no contra turno.

A proposta surgiu a partir da reflexão dos pesquisadores sobre a importância do aprofundamento teórico e prático dos conceitos relacionados à Educação Financeira nessa etapa de ensino. Este tema tem sido citado nos Parâmetros Curriculares Nacionais - PCN, nos livros didáticos, nos currículos em geral utilizado pelos professores na escola e, recentemente, na Base Nacional Comum Curricular - BNCC, o que justifica a relevância da oficina. Merece destaque o trecho registrado nos PCN afirmando que

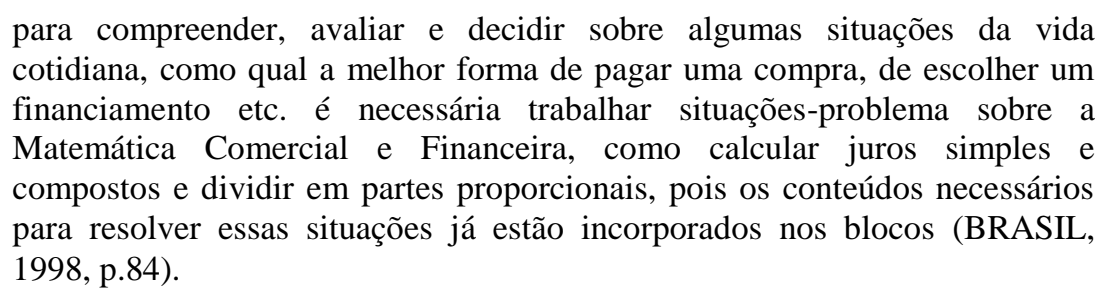

O estudo se caracterizou como um ensaio de pesquisa e, diante do levantamento bibliográfico e das observações dos autores que tratam do tema, a questão norteadora ficou assim elaborada: Quais são as possibilidades de aprendizagem sobre a Educação Financeira diante do contexto da Educação Matemática Crítica, no $9^{\circ}$ ano do ensino fundamental no âmbito de uma oficina escolar?

A partir da questão central o objetivo do estudo buscou investigar e identificar as possibilidades de ensino e de aprendizagem diante do contexto da EMC, levando em conta a realidade social e financeira dos alunos.

\section{Fundamentação Teórica}

Com a proposta da Base Nacional Comum Curricular - BNCC pode-se observar que a Educação Financiera Escolar assume um papel significativo no currículo proposto nacionalmente. Recomenda-se na nova Base que o tema perpasse todos os anos de ensino, buscando uma formação crítica para o cidadão. 


\subsection{Consequências do mundo capitalista}

Diante do mundo capitalista em que vivemos observa-se que alguns indivíduos têm dificuldade de analisar a quantidade de informação veiculadas o que pode representar um problema na organização, especialmente nos aspectos relacionados às finanças. Assim, o que se percebe é o aumento significativo de devedores no país. Segundo Kliemann, Silva e Dullius (2011), as pessoas se tornam compradores, muitas vezes desenfreados cada vez mais cedo. De acordo com estes autores esta prematuridade consumista provém, em muitos casos, dos exemplos familiares e das ofertas midiáticas que incentivam o consumismo e contribui para um descontrole financeiro.

Consumir é prazeroso, segundo Luz e Bayer (2013) os anúncios de marketing são cada vez mais atrativos sendo defendidos como "regra" por influenciadores, que muitas vezes são vistos como referência para as pessoas. Isto implica no vislumbre de bens de consumo que aparentam ser uma necessidade, a partir da proposta midiática. Os adolescentes são mais influenciáveis ainda, uma vez que estão em processo de descobrimento de seus desejos e gostos.

\footnotetext{
Em consequência do apelo visual oferecido pela mídia, os adolescentes idealizam o que gostam de ter, e como gostariam de ser, fantasiando sua auto-imagem. Ou seja, muitas vezes, consumindo aquilo que idealizam ser, obtém prazer em consumir, para satisfazer os referenciais impostos pela mídia, para formação de sua nova identidade (UTPADEL, 2007, p.8).
}

As grandes ofertas que a mídia e as empresas apresentam se mostram tentadoras e tem feito muitas pessoas perderem o controle financeiro. Resende (2013) ressalta que a "publicidade alimenta o 'desejo' pelo consumo por meio de estímulos constantes." (p. 63)

O indivíduo se deixa levar pelas informações que enchem os olhos, mas ao se render a estas ofertas estão também esvaziando o bolso, ou ainda, enchendo-se de dívidas. O poder de aquisição geralmente não é bem administrado pelas pessoas e a prova disso pode ser percebida pelos altos níveis de endividados no Brasil. De acordo com os Indicadores Econômicos SPC (Serviço de Proteção ao Crédito), Brasil e CNDL (Confederação Nacional de Dirigentes Lojistas), "o número de consumidores registrados nos cadastros de proteção ao crédito se manteve na marca dos 58,3 milhões no primeiro mês de 2017”. 
DOI: http://dx.doi.org/10.33238/ReBECEM.2019.v.3.n.2.22637

A falta de planejamento financeiro, o consumo desenfreado e o endividamento, afetam muitas famílias brasileiras, pondo em risco casamentos, a integridade dos filhos, os bens adquiridos e as próprias possibilidades de novas aquisições. De acordo com Campos e Kistemann Jr (2015), o descontrole financeiro "pode ocasionar além de brigas conjugais e outros males [...], até uma separação definitiva nesse casal ou o divórcio" (p.2), o que é muito preocupante.

A necessidade do consumo leva ao endividamento e faz o individuo não ponderar sobre a real importância do bem desejado. O que se observa por vezes, como nos afirma Luz e Bayer (2013), é que muitas pessoas "não pensam na real necessidade da aquisição daquele bem e quando percebem já estão gastando mais do que tem e do que poderiam gastar" (p. 1).

Segundo Theodoro (2011), alguns indivíduos sofrem de "analfabetismo financeiro" que, como o termo mesmo diz, é uma dificuldade de lidar com conceitos financeiros. Este desconhecimento reflete nos altos números de inadimplentes, pois o indivíduo não consegue examinar com atenção sobre a importância do bem que está adquirindo. A maioria das pessoas não avalia com calma a necessidade de aquisição de um bem e a sua possibilidade ou não de evitar a compra e, ainda, o comprador geralmente desconhece quais são as reais condições inclusas nas formas de pagamento do bem que deseja adquirir.

Vale salientar que, de acordo com as ideias apresentadas por Kliemann, Silva e Dullius (2011), são muitas as possíveis formas de pagamento presentes no mercado. O dinheiro "vivo" já não é mais a única forma de aquisição de um bem. O chequeespecial, o carnê, o empréstimo bancário e o cartão de crédito são formas de facilitar para o consumidor na hora de adquirir algo.

As formas de pagamento facilitado tendem a ser vistas como recurso único quando o mês está chegando ao fim e o salário recebido no início do mês está finalizando. A possibilidade de começar a pagar por um produto após sua aquisição pode encher os olhos de quem quer muito a mercadoria, mas não tem o dinheiro necessário para adquiri-lo à vista. Assim, com o decorrer da história, "o indivíduoconsumidor deixa de fazer parte de uma sociedade que apostava na prudência, durabilidade e segurança e passa a ser membro de uma sociedade não favorável ao planejamento, investimento e armazenamento de longo prazo" (RESENDE, 2013, p.59)

Em relação ao desejo de querer muito um produto, há uma necessidade de análise deste sentimento e uma avaliação do sentido do querer, poder e precisar. O 
DOI: http://dx.doi.org/10.33238/ReBECEM.2019.v.3.n.2.22637

julgamento da importância de determinada aquisição é essencial para o controle das finanças e no gerenciamento do lado consumista que geralmente tem sido adquirido pela maioria da população. Destaca-se o orçamento familiar como um dos primeiros caminhos para compreender a necessidade do controle financeiro, mas é preciso organização e disciplina para lidar com esta tarefa.

Todo este panorama que se obseva quando pessoas adquirem ou querem adquirir um bem justifica uma tentativa de mobilizar o jovem desde cedo para aquisição de conhecimentos sobre a matemática financeira.

\title{
2.2 Matemática Financeira e Educação Financeira
}

É importante salientar que há uma construção da Educação Financeira a partir da Matemática Financeira, que seria o processo de contextualizar e orientar sobre as aplicações deste segundo.

Para a efetivação de Educação Financeira, há necessidade de uma transição do ensino da Matemática Financeira, para o exercício da reflexão e crítica acerca de situações que influenciam a vida financeira das pessoas, não se limitando a simples aplicações de fórmulas de juros simples ou compostos ou outros cálculos mais sofisticados (CUNHA; LAUDARES, 2017, p.662).

O olhar crítico, sempre sugerido pelos estudiosos como objetivo da educação, fica muito nítido quando a Educação Financeira cumpre seu papel, de informar, conhecer e compreender as relações monetárias.

Nos textos da Estratégia Nacional de Educação Financeira - $\mathrm{ENEF}^{3}$ se apresenta uma possível compreensão do conceito de Educação Financeira:

\begin{abstract}
processo mediante o qual os indivíduos e as sociedades melhoram sua compreensão em relação aos conceitos e produtos financeiros, de maneira que, com informação, formação e orientação, possam desenvolver os valores e as competências necessários para se tornarem mais conscientes das oportunidades e dos riscos nele envolvidos e, então, poderem fazer escolhas bem informadas, saber onde procurar ajuda, adotar outras ações que melhorem o seu bem-estar. Assim, podem contribuir de modo mais consciente para a formação de indivíduos e sociedades responsáveis, comprometidos com o futuro (BRASIL, 2010, p. 57-58).
\end{abstract}

Parece importante ter conhecimento de que esta compreensão de Educação Financeira partiu de registros da ENEF, que é uma organização instituída em 2010 por decreto que tem como principal objetivo promover debates e propostas educativas voltada para a educação de consumo ampliando as compreensões dos indivíduos sobre o

\footnotetext{
${ }^{3}$ https://www.bcb.gov.br/pre/pef/port/Estrategia_Nacional_Educacao_Financeira_ENEF.pdf
} 


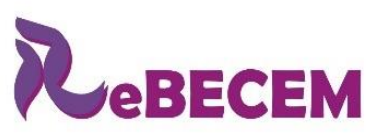

Revista Brasileira de Educação em

Ciências e Educação Matemática

DOI: http://dx.doi.org/10.33238/ReBECEM.2019.v.3.n.2.22637

assunto. As propostas sugeridas pela ENEF visam alcançar todas as faixas etárias, desde as crianças até os adultos.

Compreender possíveis estratégias necessárias nas aulas de matemática financeira para atingir uma educação financeira é essencial para que o professor que lecione conteúdos correlatos não se prenda apenas nas fórmulas e nos conceitos. Segundo pesquisas realizadas e relatadas por Teixeira (2015), que tomou como referência 161 professores que trabalhavam com a matemática financeira no ensino médio, apenas 58\% destes professores compreendiam que há diferença entre Educação Financeira e Matemática Financeira.

\title{
2.3 A Educação Financeira na formação do cidadão crítico
}

A Educação Financeira exerce um papel importantíssimo na formação dos alunos ao almejar o desenvolvimento de cidadãos participativos e críticos diante das realidades do cotidiano. Trazer assuntos como a Matemática Financeira para dentro de sala de aula, além de ser previsto pelos documentos oficiais, estreita a relação entre a teoria e prática envolvendo a matemática. Desta forma haverá uma contribuição para que os alunos se tornem capazes de usufruir de convívio social mais efetivo. Assim,

\begin{abstract}
nossa tarefa como educadores é gerar condições que alicercem o crescimento de indivíduos aptos a viver de forma plena; de modo que possam ser capazes de se integrar no convívio social, não simplesmente como coexistentes de um mesmo espaço, mas com capacidade de agir e reagir em benefício próprio e coletivo (MATURANA apud LIMA; SAUER, 2005, p. 66)
\end{abstract}

Tomando como referência neste subtítulo a "cidadania", tem-se como definição apresentada no dicionário Aurélio (FERREIRA, 1986, p.403) que cidadão é aquele sujeito "no gozo dos direitos civis e políticos de um Estado, ou no desempenho de seus deveres para com este". Sendo assim, antes de desempenhar os direitos e deveres como cidadão, o indivíduo precisa conhecê-los e compreendê-los.

Como ressalta a Lei de Diretrizes e Bases (1996), seria interessante que no ambiente escolar fosse estimulado a busca pelos conhecimentos do cidadão, uma vez que "a educação básica tem por finalidades desenvolver o educando, assegurar-lhe a formação comum indispensável para o exercício da cidadania” (BRASIL, 1996, Art. 22.)

Trazer para a sala de aula conteúdos que sejam significativos para os alunos podem facilitar a aprendizagem. Matemática Financeira permite ao professor contextualizar com certa perspicácia situações reais e, assim, pode ser um caminho para 
DOI: http://dx.doi.org/10.33238/ReBECEM.2019.v.3.n.2.22637

facilitar a apresentação de diversos conteúdos não exclusivos da Matemática Financeira.

A valorização de situações vividas pelo aluno parece ser um trunfo para o professor como afirmam Miranda e Philippsen (2014).

\begin{abstract}
Nas atividades de sala de aula é fundamental que se valorize o contexto do educando à medida que for se deparando com a situação que ele enfrenta no dia-a-dia, perceberá a importância do saber matematicamente elaborado para auxiliá-lo na resolução dos mesmos, é preciso colocar o aluno em uma posição que exigirá dele o pensar, o organizar de ideias e estratégias, o lançar mão de um leque de habilidades (MIRANDA; PHILIPPSEN, 2014, p.4)
\end{abstract}

Corroborando com as ideias dos autores, Pelicioli (2011, p.13) afirma que "em um país com extremas desigualdades sociais como o Brasil, a inserção da Educação Financeira no processo educacional, desenvolvido nas escolas, mostra-se uma medida urgente". O conhecimento matemático, ou a falta dele, tem um caráter que permite levar a inclusão ou exclusão dos cidadãos. Neste sentido, a educação pode ser percebida como o divisor de águas no que se refere às disparidades econômicas e sociais da comunidade atual,

onde os bens e os serviços existem para serem financiados, onde as transações comerciais ocorrem geralmente através desta modalidade, entre empresas e empresas, empresas e pessoas, não seria justo, portanto, que apenas uma das partes envolvidas nestas relações tenha consciência dos princípios básicos do sistema financeiro, que a compreensão do plano macroeconômico, da força do capital financeiro e das suas consequiências sobre as relações de poder e sobre formas conscientes de consumir não fossem temáticas discutidas nas escolas (JUNIOR; JOUCOSKI, 2008, p.2)

Parece inquestionável a necessidade de que seja discutido nas escolas questões relacionadas à consumo e noções sobre Matemática Financeira. Carvalho (1999, p.9) alerta que "a escola não pode se furtar à responsabilidade de promover a educação para o consumo, provocando reflexões, dando acesso a informações e instrumentalizando sua comunidade para as tomadas de decisão". Os dados citados pelo Serviço de Proteção ao Crédito (SPC) ressaltam a importância de se entender realmente a matemática que há por trás das compras, dos empréstimos, financiamentos, parcelas, e outros tantos detalhes da Matemática Financeira. Parece indubitável que a informação e o conhecimento tornam o cidadão mais crítico e preparado para as realidades do cotidiano.

Como educadores, parece prudente ressaltar a importância de se atentar que a Matemática Financeira pode beneficiar a aquisição de uma leitura crítica do mundo e, ainda, acreditar na possibilidade de se explorar o tema dentro da sala de aula elevando o potencial analítico do aluno, contribuindo para a realização de escolhas mais 


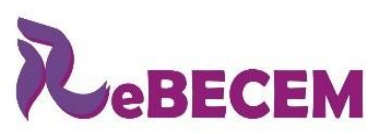

Revista Brasileira de Educação em

Ciências e Educação Matemática

ISSN 2594-9179

DOI: http://dx.doi.org/10.33238/ReBECEM.2019.v.3.n.2.22637

apropriadas e conscientes. Tarefas que abordem conceitos financeiros tendem a desenvolver no aluno a autonomia, a prudência e o equilíbrio, aspectos primordiais para se viver bem em sociedade. Para Campos (2013) o objetivo desta proposta de autonomia para o aluno é possibilitar "uma passagem progressiva de situações onde o aluno é conduzido por outras pessoas, a situações dirigidas por ele próprio" (p. 49). Fonseca (1995) afirma que

\begin{abstract}
as linhas de frente da Educação Matemática têm hoje um cuidado crescente com o aspecto sociocultural da abordagem matemática. Defendem a necessidade de contextualizar o conhecimento matemático a ser transmitido, buscar as suas origens, acompanhar a sua evolução, explicitar a sua finalidade ou o seu papel na interpretação e na transformação da realidade do aluno. É claro que não se quer negar a importância da compreensão, nem tampouco desprezar a aquisição de técnicas, mas busca-se ampliar a repercussão que o aprendizado daquele conhecimento possa ter na vida social, nas opções, na produção e nos projetos daquele que o aprende. (FONSECA, 1995, p.48)
\end{abstract}

A Matemática Financeira, embora não seja talvez um conteúdo considerado novo, pode ser atualizado e ter diferentes estratégias para mobilizar os alunos a se interessar pelo tema, pois este tema explora um aspecto muito presente na vida de todos, que são as finanças, o que difere de alguns outros conteúdos. Muitas vezes percebe-se que as maiores dúvidas dos alunos se relacionam à aplicabilidade daquilo que é estudado dentro da sala de aula. No que tange ao aspecto de relacionar o estudado com a realidade, como nos diz Junior e Joucoski (2008, p.2), a "Matemática Financeira, neste sentido pode auxiliar nesta correspondência, já que a sua problematização é óbvia”.

Recomenda-se que os problemas trabalhados em sala de aula sejam sempre os mais reais possíveis, aproximando a verdade vivida pelo aluno. Que o estudante seja estimulado a fazer análises dos dados e que construam conjecturas a partir das observações indo além das operações numéricas prontas e acabadas. Fernandes (2006) afirma que contextualização se caracteriza pelo "fato de que todo conhecimento envolve uma relação entre sujeito e objeto, ou seja, quando se trabalha o conhecimento de modo contextualizado a escola está retirando o aluno da sua condição de expectador passivo." (p. 3)

A exploração deste conteúdo se mostra como uma oportunidade de se fazer observações subjetivas e ajudar o aluno a moldar e compreender as situações propostas. Como questiona Freire (2011)

Por que não discutir com os alunos a realidade concreta que se deva associar à disciplina cujo conteúdo se ensina [...]? Por que não estabelecer uma "intimidade" entre os saberes curriculares fundamentais aos alunos e a experiência social que eles têm como indivíduos? (FREIRE, 2011, p. 32). 
Neste sentido, a Matemática Financeira pode estreitar a compreensão do aluno sobre o conteúdo trazendo a aplicabilidade que tanto os estudantes buscam nas aulas de matemática.

Mesmo ainda não sendo um conteúdo obrigatório dentro do currículo da educação básica, a educação financeira apresenta-se como uma necessidade de tema transversal, entrando de diferentes formas nos muros da escola.

No trabalho intitulado Um programa de Educação Financeira para a Matemática Escolar da Educação Básica, Silva e Powell (2013) sugerem uma proposta de currículo organizada em quatro eixos norteadores, no qual os tópicos devem ser discutidos durante toda a formação da educação básica:

I - Noções básicas de Finanças e Economia: Nesse eixo os temas de discussão são, por exemplo, o dinheiro e sua função na sociedade; a relação entre dinheiro e tempo - um conceito fundamental em Finanças; as noções de juros, poupança, inflação, rentabilidade e liquidez de um investimento; as instituições financeiras; a noção de ativos e passivos e aplicações financeiras. II - Finança pessoal e familiar: Nesse eixo, serão discutidos temas como, por exemplo: planejamento financeiro; administração das finanças pessoais e familiares; estratégias para a gestão do dinheiro; poupança e investimento das finanças; orçamento doméstico; impostos.

III - As oportunidades, os riscos e as armadilhas na gestão do dinheiro numa sociedade de consumo: Nesse eixo, serão discutidos temas como, por exemplo: oportunidades de investimento; os riscos no investimento do dinheiro; as armadilhas do consumo por trás das estratégias de marketing e como a mídia incentiva o consumo das pessoas.

IV - As dimensões sociais, econômicas, políticas, culturais e psicológicas que envolvem a Educação Financeira: Nesse eixo, serão discutidos temas como: consumismo e consumo; as relações entre consumismo, produção de lixo e impacto ambiental; salários, classes sociais e desigualdade social; necessidade versus desejo; ética e dinheiro (SILVA; POWELL, 2013, p. 14)

Entretanto, não se pretendeu no ensaio de pesquisa afirmar que são suficientes propostas de educação financeira para sanar os problemas de mau uso do dinheiro ou inadimplência, ou seja, não se pretendeu com o estudo afirmar que aquele que for educado financeiramente na escola será um consumidor consciente, uma vez que a educação apresenta possibilidades, mas cada indivíduo assume uma posição de tomada de decisão.

\subsection{A Educação Matemática Crítica e o papel da Matemática Financeira}

A Educação Matemática Crítica - EMC surge nos anos 1980 dedicando-se a estreitar a relação entre Matemática e aspectos políticos, democráticos e sociais. Skovsmose (2001), principal estudioso e divulgador da EMC no Brasil, sinaliza o papel 


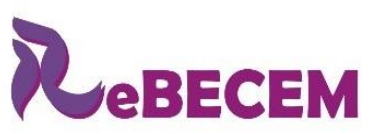

\title{
Revista Brasileira de Educação em \\ Ciências e Educação Matemática \\ ISSN 2594-9179
}

DOI: http://dx.doi.org/10.33238/ReBECEM.2019.v.3.n.2.22637

que a matemática tem na formação dos indivíduos, e apresenta como esta matemática pode ter um direcionamento crítico a partir das propostas do professor.

Nesta perceptiva, a EMC converge para uma prática na qual o aluno tem papel ativo na produção de conhecimento, levantando questionamentos e é tratado como centro no processo de ensino e de aprendizagem, buscando minimizar deficiência crítica deste conteúdo escolar. Desvincula-se a matemática de processo engessados, distantes do mundo real e das necessidades deste ambiente.

Skovsmose (2000) apresenta os cenários para investigação, ambiente que pretende propiciar uma aprendizagem crítica, como sendo

\begin{abstract}
aquele que convida os alunos a formularem questões e procurarem explicações. O convite é simbolizado pelo "o que acontece se...T" do professor. O aceite dos alunos ao convite é simbolizado por seus "Sim, o que acontece se... T". Dessa forma, os alunos se envolvem no processo de exploração. O "Por que isto...?" do professor representa um desafio e os "Sim, por que isto...T" dos alunos indica que eles estão encarando o desafio e que estão procurando explicações. Quando os alunos assumem o processo de exploração e explicação, o cenário para investigação passa a constituir um novo ambiente de aprendizagem (SKOVSMOSE, 2000, p. 6).
\end{abstract}

Considerando os cenários para investigação pode-se pensar no lugar do aluno como maior responsável por seu aprendizado. A partir dos paradigmas da sala de aula, que são a relação entre os exercícios e os cenários para investigação, o autor propõe um quadro sintetizando estas relações.

Quadro 1: Ambientes de aprendizagem segundo Skovsmose (2000)

\begin{tabular}{|l|l|l|}
\hline & \multicolumn{1}{|c|}{ Exercícios } & \multicolumn{1}{c|}{ Cenários para Investigação } \\
\hline Referências à matemática pura & Ambiente (1) & Ambiente (2) \\
\hline Referências à semi-realidade & Ambiente (3) & Ambiente (4) \\
\hline Referências à realidade & Ambiente (5) & Ambiente (6) \\
\hline
\end{tabular}

Fonte: Skovsmose (2000)

Compreendendo cada aspecto do quadro proposto, os ambientes de referência a matemática pura são atividades que objetivam resolução de cálculos e de respostas acabadas, o que ocorre na diferenciação é que os exercícios são mais diretos e sem nenhuma preocupação com o processo, diferente dos cenários para investigação. No caso da semi-realidade, as tarefas tratam de assuntos até contextualizados, entretanto, não há conexão obrigatória com o real, no ambiente (3) espera-se apenas que o aluno, a partir de uma situação artificial, determine o que se pede implicitamente. A semirealidade vivida no ambiente (4) pode ser considerada, no caso da educação financeira, as situações hipotéticas como porcentagens de juros acima do aceitável, valores irreais, mas que mesmo assim, permitem analises críticas e debates no processo. 


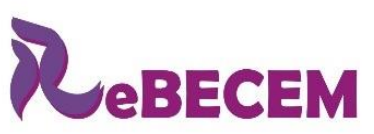

Revista Brasileira de Educação em

Ciências e Educação Matemática

DOI: http://dx.doi.org/10.33238/ReBECEM.2019.v.3.n.2.22637

Os ambientes de aprendizados nas referências das realidades, baseando-se nos exercícios, têm por finalidade tratar de assuntos realísticos, mas que por sua vez pretendem tratá-los como meio para reprodução de algum conteúdo. Segundo Moreira (2014), em resumo, o paradigma do exercício, proposto no Quadro 1, “é comumente associado ao termo "ensino tradicional"” (p. 51).

Deste modo, o Cenário para Investigação configura-se em um ambiente propicio ao diálogo e debate, no qual o professor e os alunos devem estar de acordo em participar da produção deste ambiente. É interessante compreender que em um Cenário para Investigação os estudantes são direcionados pelo educador a produzir e compreender significados para conceitos matemáticos a partir de atividades propostas.

Neste sentido, Skovsmose estuda e apresenta termos advindos da literacia de Paulo Freire (2011). Os termos apresentados por este autor são: materacia e matemácia, que são sinônimos e objetivam o intuito de ensino da matemática mais crítico, social e contextualizado. Skovsmose (2000, p. 02) admite que a materacia "não se refere apenas às habilidades matemáticas, mas também à competência de interpretar e agir numa situação social e política estruturada pela matemática".

Com estudos mais recentes, Pessoa, Muniz Jr. e Kistemann Jr. (2018) assumem ainda o termo Literacia Financeira, que segundo os autores, "seria uma competência adquirida e desenvolvida por um indivíduo-consumidor em contextos socioeconômicos em uma sociedade de consumo líquido-moderna em que a tomada de decisão faz parte das ações deste indivíduo" (p. 4), ou seja, situações nas quais o indivíduo se apropria de uma postura de conhecedor de suas funções enquanto parte do grupo de consumidores.

No âmbito de Educação Financeira, Kistemann Jr (2011) concebe o termo Matemácia Financeiro-Econômica, definido como sendo "a habilidade de análise e reflexão com a decorrente tomada de decisão acerca de situações de consumo" (p. 97). É este contexto que o ensaio de pesquisa realizado e relatado no Trabalho Final de Curso abordou, buscando sempre explorar com os alunos um olhar crítico diante dos acontecimentos, e quando este o fizer não abafar suas considerações, como muitas vezes se observa na sociedade quando se julga importuno as considerações de consumidores jovens. 


\section{Aspectos Metodológicos}

O ensaio de pesquisa teve abordagem metodológica qualitativa e, justificou-se a adoção da metodologia, a partir das considerações de André (2013) que afirma que estas abordagens "se fundamentam numa perspectiva que concebe o conhecimento como um processo socialmente construído pelos sujeitos nas suas interações cotidianas, enquanto atuam na realidade, transformando-a e sendo por ela transformados" (p. 97).

Os alunos convidados a participar da oficina eram alunos de uma turma do $9^{\circ}$ ano do ensino fundamental da rede pública de Uberlândia-MG. A proposta foi apresentada ao professor da turma, que colaborou sugerindo alguns ajustes no plano de aula de acordo com as necessidades da turma. A oficina ocorreu na sala de vídeo da escola, uma vez que o planejamento dos encontros contava com recurso digital e as atividades foram apresentadas com auxílio do programa Power Point.

Os alunos receberam no primeiro encontro o material necessário para a oficina. Este material era composto de um caderno, uma caneta, e calculadoras. As atividades sempre buscavam o desenvolvimento em grupo, ressaltando o objetivo de trabalhar os cenários para investigação com situações problemas.

Após apresentação e divulgação da oficina aos alunos, houve a necessidade de se providenciar uma lista de presença a fim de viabilizar a preparação dos materiais. Houve interesse de 19 alunos. Vale salientar que os encontros (oficinas) aconteceram no contra turno do período em que os alunos estudavam na escola. Cada encontro teve duração de cerca de duas horas.

A proposta da oficina com os alunos se caracterizava como um estudo sobre a Educação Financeira, com uma abordagem na Matemática Financeira. Cada encontro foi dividido em duas partes, com duração de duas horas no total. A primeira parte voltada para o estudo de conteúdos matemáticos que ajudam na aprendizagem sobre finanças, a partir de atividades investigativas e compreensão de conceitos relacionados. Também foram explorados temas como: porcentagens, conceito de juros simples e composto e razão e proporção.

O segundo momento, voltado para leitura e debate com os alunos, quando cada grupo de alunos recebia um material com tema específico. Cada grupo era orientado a ler e refletir dialogando com os colegas sobre a proposta. Em seguida, os alunos eram convidados a disporem suas carteiras em forma de roda para que houvesse um debate no qual cada grupo teria a oportunidade de expor o que havia sido lido e apresentar suas 


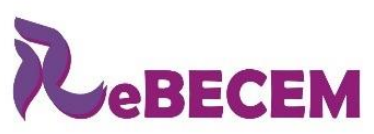

Revista Brasileira de Educação em

Ciências e Educação Matemática

DOI: http://dx.doi.org/10.33238/ReBECEM.2019.v.3.n.2.22637

considerações. A autonomia e a reflexão foram sempre instigadas, a partir da Educação Matemática Crítica levando os alunos a apresentarem diferentes pontos de vista e compreenderem a importância do trabalho em grupo e do diálogo crítico e construtivo.

\section{Descrição e análise dos dados}

Com base no referencial teórico que aborda o ensino da Matemática Financeira com viés na Educação Financeira, foi elaborado o plano de aula da oficina. O trabalho com a Educação Financeira se apresenta como uma via possível para abordar assuntos do currículo da matemática que por vezes são incompreendidos pelos alunos. Nesta oficina enxergou-se uma oportunidade de associar conceitos já conhecidos pelos alunos com os assuntos das finanças e da economia.

No primeiro encontro, além da leitura das orientações e resposta de um breve questionário, foram propostas tarefas envolvendo o conteúdo de porcentagem, sendo considerado como uma revisão importante para o decorrer da oficina. Figueiredo (2013) afirma que a ideia de porcentagem "precisa ser trabalhada de forma atrativa para os alunos, pois seu uso no dia a dia é frequente. Ao irmos a um supermercado, a uma loja, a um banco é impossível não nos depararmos com taxas percentuais" (p. 2). Em seguida foram propostas atividades envolvendo porcentagem, quando cada grupo foi à lousa resolvê-las.

O segundo encontro foi planejado a partir da sequência de conceitos elaborada pela professora, uma das autoras. Estipulou-se que esse primeiro momento seria dedicado exclusivamente para o estudo dos conceitos de juros simples e compostos para que pudessem ser explorados Nesta etapa foi proposto um problema em que uma determinada quantia teria sido dada como um presente para os próprios alunos, observando a realidade dos mesmos e a possiblidade de contextualização do problema, criando um ambiente realista nos Cenários para Investigação de Skovsmose (2001). Esta quantia apresentava um rendimento de $10 \%$ ao ano e a indagação era referente à quantia obtida após três anos. Os alunos deveriam se dedicar à tarefa de modo a encontrar a melhor opção e descrevê-la. Acreditando no que Mendes (2009) afirma em seu trabalho, que o aluno "aprende a pensar por si mesmo, levantando hipóteses, testando-as, tirando conclusões e até discutindo-as com os colegas" (p.71), sugeriu-se que os alunos fossem ao quadro explicar seus pensamentos, sugestões e elaborações.

É papel da escola desenvolver uma educação que não dissocie escola e sociedade, conhecimento e trabalho e que coloque o aluno ante desafios que 
DOI: http://dx.doi.org/10.33238/ReBECEM.2019.v.3.n.2.22637

lhe permitam desenvolver atitudes de responsabilidade, compromisso, crítica, satisfação e reconhecimento de seus direitos e deveres. Nesse aspecto, a Matemática pode dar sua contribuição à formação do cidadão ao desenvolver metodologias que enfatizem a construção de estratégias, a comprovação e justificativa de resultados, a criatividade, a iniciativa pessoal, o trabalho coletivo e a autonomia advinda da confiança na própria capacidade para enfrentar desafios (BRASIL, 1998, p. 27).

A proposta de instigar o aluno a pensar sobre possível rendimento de uma quantia recebida foi desafiante e permitiu o desenvolvimento de atitude responsável e crítica, conforme afirma o trecho o documento acima descrito.

$\mathrm{Na}$ sequência foi proposto a exposição das fórmulas de juros simples e compostos de maneira construtiva, considerando cada passo da dedução, deixando explícitos os cálculos feitos. Esta tarefa foi proposta utilizando apresentação multimídia, como recurso de transição paulatina do texto/cálculo, na qual cada passo era escrito e discutido pouco a pouco.

A segunda parte do encontro dois foi dedicada à leitura do primeiro módulo do Caderno de Educação Financeira Gestão de Finanças Pessoais tratando da relação do indivíduo com o dinheiro, propondo interpretações construtivas e uma discussão pautada nas observações realizadas a partir da leitura e acrescida das experiências dos próprios alunos. Neste momento a turma foi organizada em grupos para propiciar a interação entre os participantes de um mesmo grupo. Os autores do Caderno, utilizado como referência, apresentaram alguns objetivos para o primeiro módulo, descritos a seguir

-Compreender a relação cotidiana das pessoas com os seus recursos financeiros e fazer escolhas cada vez mais conscientes.

-Refletir sobre seus sonhos e sobre como transformá-los em realidade por meio de projetos.

-Avaliar suas necessidades e desejos e como os efeitos de suas escolhas afetam a qualidade de vida no presente e no futuro (BRASIL, 2013, p. 10).

Figura 1: Roda de discussão de um dos encontros

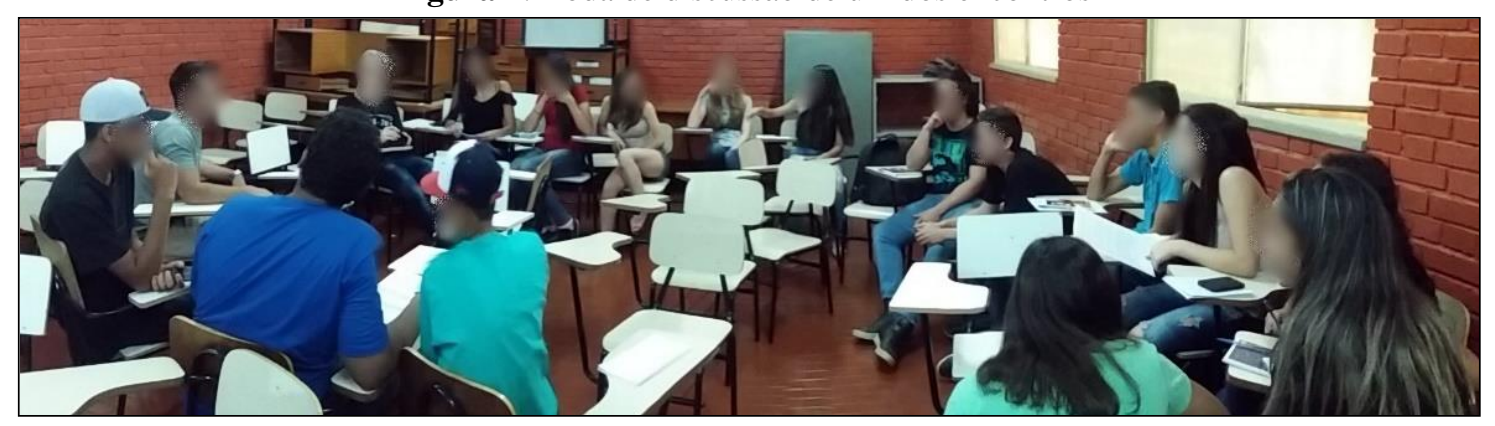

Fonte: Arquivos dos autores 


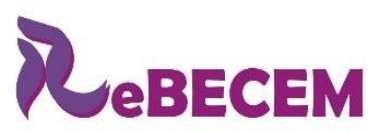

Revista Brasileira de Educação em

Ciências e Educação Matemática

ISSN 2594-9179

DOI: http://dx.doi.org/10.33238/ReBECEM.2019.v.3.n.2.22637

$\mathrm{O}$ terceiro encontro foi direcionado à apresentação dos termos envolvidos na Matemática Financeira. Os principais tópicos trabalhados foram: Taxa de Juros; Capital; Período; Juros Simples; Montante; Juros Compostos e Orçamento. Para o momento de leitura e discussão foi utilizado como base o terceiro módulo do Caderno, intitulado Uso do Crédito e Administração das Dívidas. As discussões nesta etapa foram direcionadas com os temas apresentados no Quadro 2. Neste ponto da oficina ficou evidente a importância do diálogo e da troca de experiências, uma vez que a ideia de orçamento e gestão orçamentária se mostrava diferente para cada aluno, de acordo com sua realidade familiar.

\begin{tabular}{|c|c|}
\hline Grupo 01 & $\begin{array}{l}\text { O que é orçamento? } \\
\text { Elaboração do orçamento }\end{array}$ \\
\hline Grupo 02 & $\begin{array}{l}\text { Como elaborar um orçamento } \\
\text { Gestão orçamentária } \\
\text { Participação da família no orçamento }\end{array}$ \\
\hline Grupo 03 & $\begin{array}{l}\text { Definição de crédito } \\
\text { Valor do dinheiro no tempo } \\
\text { Atenção aos juros }\end{array}$ \\
\hline Grupo 04 & $\begin{array}{l}\text { Uso do crédito } \\
\text { Dívidas }\end{array}$ \\
\hline
\end{tabular}

Fonte: Arquivos dos autores

O quarto encontro teve como objetivo compreender o tema Razão e Proporção. Como introdução utilizou-se um problema em que havia uma ilustração de uma oferta de supermercado e os alunos foram solicitados a encontrar qual seria a melhor aquisição. Foram propostos alguns exercícios de fixação abordando este tema. Neste encontro, as leituras versavam sobre planejando o consumo, recomendações para o consumo, dicas para o consumidor e o consumo consciente.

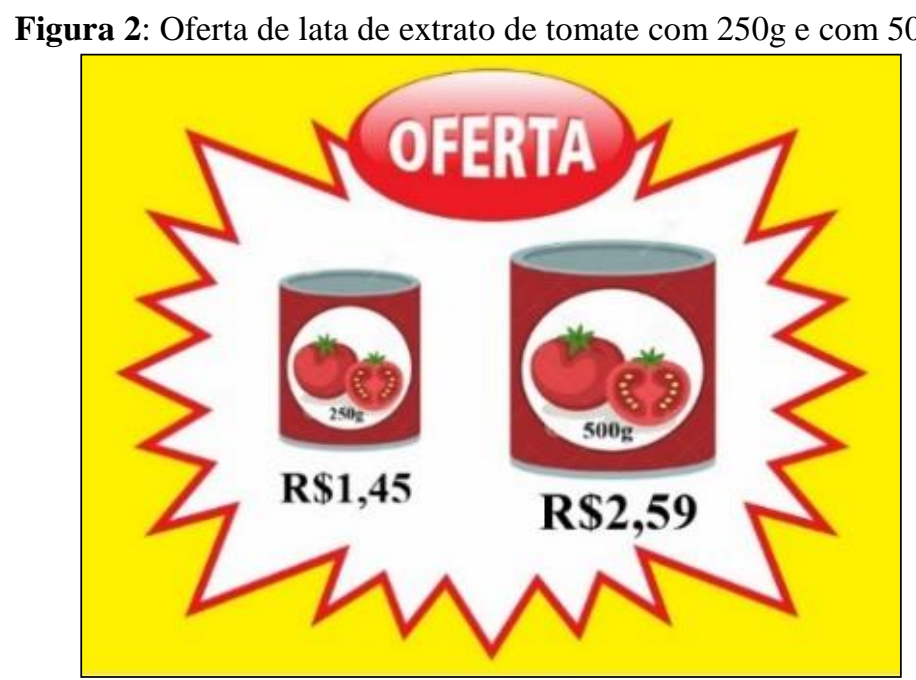

Fonte: Arquivos dos autores 


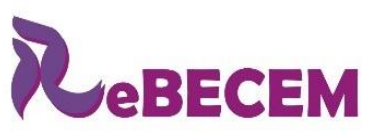

Revista Brasileira de Educação em

Ciências e Educação Matemática

DOI: http://dx.doi.org/10.33238/ReBECEM.2019.v.3.n.2.22637

$\mathrm{O}$ encontro de número cinco contou com uma proposta para possibilitar o conhecimento de termos do universo financeiro. Nesta etapa, o foco se apresentava com assuntos gerais, temas importantes para o consumidor conhecer as funções, vantagens e desvantagens de opções de aquisições de bens e produtos presentes no mercado. Foram explorados conceitos como IPCA, SELIC, Imposto de Renda, Empréstimo, Inflação, Consórcio e Financiamento.

Como complemento ao assunto foi recomendado que todos assistissem um vídeo $^{4}$ para possibilitar a compreensão dos termos em contextos que aproximassem da realidade. Neste vídeo a apresentadora no filme explica de forma simples a aplicabilidade dos conceitos que envolvem poupanças e investimentos.

O último encontro foi planejado levando em consideração o decorrer da oficina e contou com uma proposta mais prática, em que os alunos, organizados em pequenos grupos, deveriam pensar em seus orçamentos agindo como família. O salário de cada família fictícia foi sorteado entre os grupos. Cada grupo/família deveria lembrar-se da necessidade de moradia, transporte, lazer, alimentação, pagamento de contas de água e esgoto, energia, telefone, internet e TV a cabo.

Quadro 3: Itens presentes no orçamento das famílias

\begin{tabular}{|l|c|}
\hline 1 & Moradia \\
\hline 2 & Transporte \\
\hline 3 & Lazer \\
\hline 4 & Alimentação \\
\hline 5 & Educação \\
\hline 6 & Saúde \\
\hline 7 & Água e esgoto \\
\hline 8 & Energia \\
\hline 9 & Telefone, internet e TV \\
\hline
\end{tabular}

Fonte: Arquivos dos autores

Nenhum dos itens do Quadro 3 poderia ser descartado e, além disso, a troca ocorreria apenas em um segundo momento, ou seja, uma casa só seria alugada para uma única família, e caso houvesse arrependimento, o grupo poderia trocar depois.

a contribuição da matemática nas tarefas que lidam com o dinheiro não reside
apenas em apoiar as ações do cálculo correto, no que se refere às
especificações de determinadas somas ou casos como troco ou pagamento de
um total no caixa. Diversos conceitos e procedimentos de matemática são
acionados para entendermos nossos holerites (contracheques), calcular ou
avaliar aumentos e descontos nos salários, aluguéis, mercadorias, transações
financeiras, entre outros (CARVALHO, 1999, p. 61).

${ }^{4}$ https://www.youtube.com/watch?v=ukZCWZTzg4E 


\section{$R_{\text {eBECEM }}$}

Revista Brasileira de Educação em

Ciências e Educação Matemática

ISSN 2594-9179

DOI: http://dx.doi.org/10.33238/ReBECEM.2019.v.3.n.2.22637

Considerando a afirmação de Carvalho (1999), a proposta de ensino levou em consideração detalhes da vida em família que não se limitava a cálculos envolvendo dinheiro. Esta atividade teve ainda a presença de imprevistos em que os alunos deveriam direcionar uma parte do salário para pagar o ocorrido, buscando analisar a importância de se ter sempre uma reserva para necessidades quaisquer.

A proposta consistiu em apresentar aos alunos fichas com possíveis bens e serviços essenciais. Cada grupo deveria, com a direção daquele que seria responsável pelo orçamento familiar, escolher um de cada item do Quadro 3. Em seguida, os a equipe deveria somar seus gastos a observar o salário sorteado de cada grupo, os salários variavam entre 1,5 até 4 salários mínimos. A Figura 3 apresenta o material que os alunos deveriam preencher.

Figura 3: Material preenchido por uma das famílias

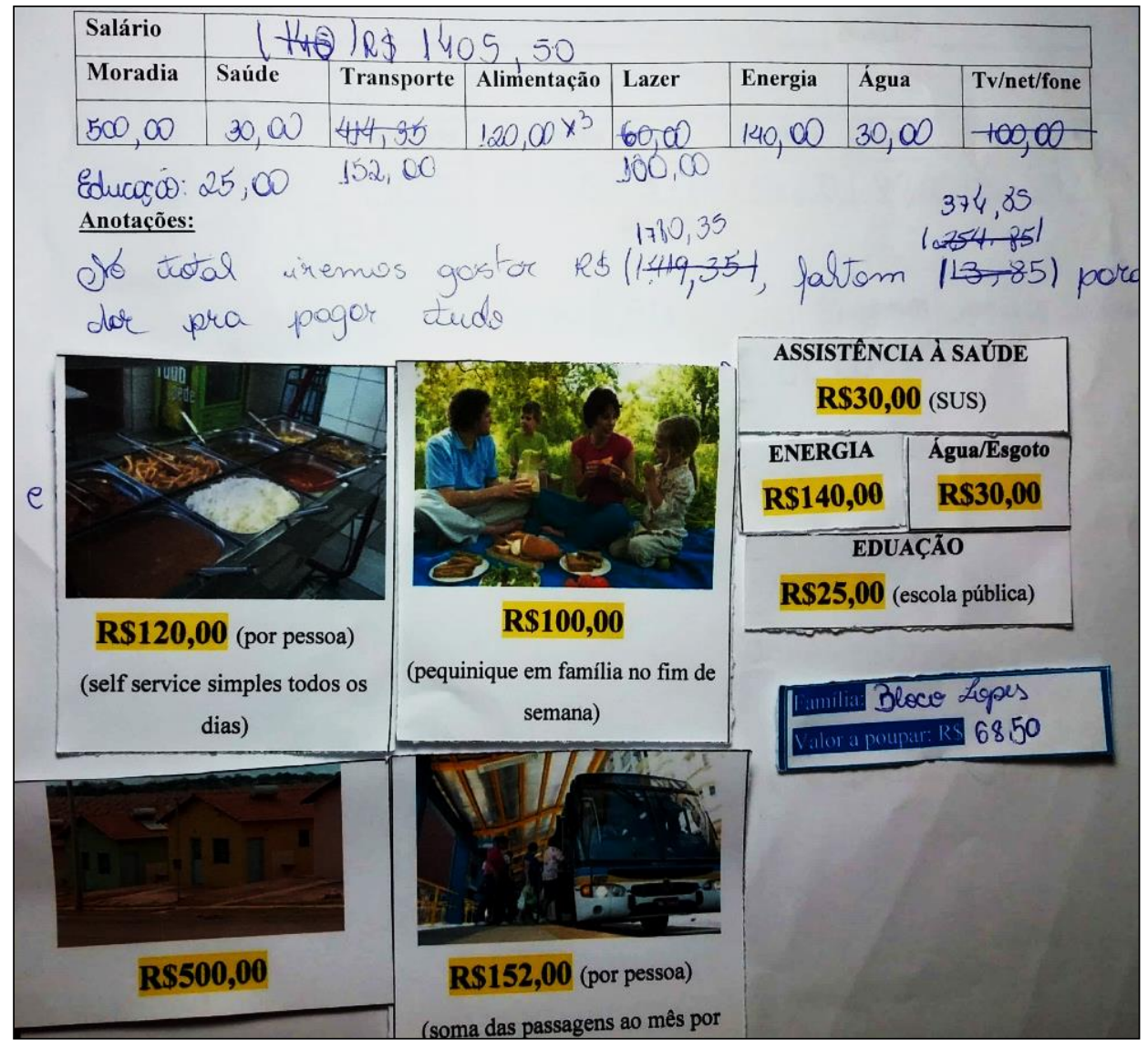

Fonte: Arquivos dos autores

Acredita-se que esta experiência trouxe benefícios para o processo de aprendizagem e para aprimorar o pensamento crítico do aluno. Santos e Pessoa (2016, p.43), afirmam que nas tarefas propostas dentro da sala de aula se faz interessante que o professor busque sempre "propiciar aos alunos momentos de reflexão nos quais eles 


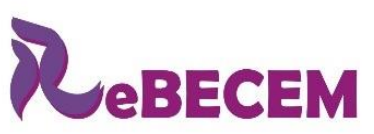

Revista Brasileira de Educação em

Ciências e Educação Matemática

DOI: http://dx.doi.org/10.33238/ReBECEM.2019.v.3.n.2.22637

possam ser colocados diante de situações diversas e que discutam, nestas situações, as possibilidades a serem tomadas e as consequências advindas a partir das escolhas". Desta forma, a proposta oferecida na oficina evidencia que os alunos foram levados a pensar e criar soluções viáveis de organização para sempre terem em seus orçamentos, uma porção de reserva emergencial.

Por fim, na etapa de conclusão da oficina os alunos foram convidados a fazer uma reflexão mais profunda de todo o encontro, em forma de diálogo.

A10: Eu adorei todos os encontros, passei a pensar duas vezes antes de comer na rua, as vezes eu espero chegar em casa.

A18: Na minha casa, passamos a falar ainda mais sobre isso, meus pais abriram espaço para eu contar um pouco do que vimos aqui, principalmente sobre organização das contas.

PP: Que bacana gente.

A02: Professora, eu espero que mais jovens como nós possam ter esta experiência, é claro que não saímos daqui economistas, mas você nos instigou a pensar sobre o dinheiro e como estamos gastando ele.

A10: É verdade. A gente só ia pensar nisso quando começasse a trabalhar, como se não tivéssemos responsabilidades no orçamento em nossas casas.

PP: Eu fico muito feliz, e espero sim ter mais oportunidades como essa, e que vocês sejam consumidores conscientes daqui para frente.

Poucos alunos quiseram se manifestar de forma mais densa, mas a fala sintética da maioria apresentou pontos que não haviam refletido ainda, como orçamento, compreensão de necessidade e desejo e, sobretudo, parece que os alunos compreenderam que o dinheiro não é um vilão, mas apenas precisa ser compreendido de forma correta.

\section{Considerações finais}

Os principais resultados deste estudo sinalizam possibilidades de acrescentar à Educação Financeira, oriunda da Matemática Financeira Crítica, momentos de construção de conhecimento e enriquecimento pessoal e do grupo, além de propiciar o diálogo e o trabalho colaborativo entre os envolvidos. A oficina proporcionou aos alunos e à professora oportunidades de reflexões e diálogos, que valorizaram as experiências pessoais e as possibilidades de aperfeiçoamento de opiniões. 


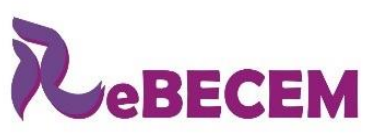

Revista Brasileira de Educação em

Ciências e Educação Matemática

DOI: http://dx.doi.org/10.33238/ReBECEM.2019.v.3.n.2.22637

Outra situação que enfatiza a necessidade de reflexão e aperfeiçoamento na oferta de propostas semelhantes se verificou na organização dos grupos, pois os alunos tinham autonomia para escolher seus grupos. A escolha livre resultou na presença de grupos muito grandes ou muito pequenos e alunos muito tímidos juntos, dificultando a comunicação do grupo com a turma.

Compreende-se que este tipo de proposta de ensino requer muito estudo e planejamento, mas também se pode constatar a viabilidade das tarefas veiculadas dentro da sala de aula durante o ano letivo, uma vez que as propostas de ensino contextualizam os conceitos pertinentes do currículo do $9^{\circ}$ ano do ensino fundamental.

Salienta-se que a professora teve sempre o cuidado de optar por propostas que levassem os alunos a exploração, debate e postura autônima nos procedimentos, criando Cenários para Investigação, como sugere Skovsmose (2000).

\section{Referências}

ANDRÉ, M. O que é um Estudo de Caso Qualitativo em Educação? Revista da Faeeba: Educação e Contemporaneidade, Salvador, v. 22, n. 40, p.95-103, jul./dez. 2013.

BRASIL. Ministério da Educação. LDB - Lei no 9394/96, de 20 de dezembro de 1996. Ministério de Educação e Cultura. Estabelece as diretrizes e bases da Educação Nacional. Brasília: MEC, 1996. Disponível em:

http://portal.mec.gov.br/seed/arquivos/pdf/tvescola/leis/lein9394.pdf. Acesso em: 10 out. 2017.

BRASIL. Secretaria de Educação Fundamental. Parâmetros Curriculares Nacionais: terceiro e quarto ciclos: apresentação dos temas transversais. Brasília: MEC/SEF, 1998.

BRASIL. Organização para a Cooperação e Desenvolvimento Econômico (OCDE). BRASIL: Implementando a Estratégia Nacional de Educação Financeira. 2010.

Disponível em:

<http://www.bcb.gov.br/pre/pef/port/Estrategia_Nacional_Educacao_Financeira_ENEF.pdf.> Acesso em: 24 de julho de 2019.

BRASIL. Banco Central do Brasil. Caderno de Educação Financeira - Gestão de Finanças Pessoais (Conteúdo Básico). Brasília, DF: Banco Central do Brasil. 2013. Disponível em: https://www.bcb.gov.br/pre/pef/port/caderno_cidadania_financeira.pdf. Acesso em: 17 outubro. 2017.

CAMPOS, A. B. Investigando como a educação financeira crítica pode contribuir para tomada de decisões de consumo de jovens-indivíduos-consumidores (JIC's). 2013.

Dissertação (Mestrado Profissional em Educação Matemática) - Universidade Federal de Juiz de Fora, Juiz de Fora, 2013.

CAMPOS, A. R.; KISTEMANN JR, M. A. Planejamento Financeiro: Cada um deve ter o seu? In: ENCONTRO MINEIRO DE EDUCAÇÃO MATEMÁTICA, 7., 2015, São João del-Rei.

Anais... Juiz de Fora: UFJF, 2015. p. 1-12. 
DOI: http://dx.doi.org/10.33238/ReBECEM.2019.v.3.n.2.22637

CARVALHO, Valéria de. Educação Matemática: Matemática e Educação para o Consumo. 1999. Dissertação (Mestrado em Educação) - Faculdade de Educação, Universidade Estadual de Campinas, Campinas, 1999.

CUNHA, C. L. da; LAUDARES, J. B. Resolução de Problemas na Matemática Financeira para Tratamento de Questões da Educação Financeira no Ensino Médio. Bolema, Rio Claro, v. 31, n. 58, p. 659-678, ago. 2017.

FERNANDES, S. da S. A contextualização no ensino de matemática - um estudo com alunos e professores do ensino fundamental da rede particular de ensino do Distrito Federal. Trabalho de Concusão de Curso (Licenciatura em Matemática) - Universidade Católica de Brasília, Brasília, 2006.

FERREIRA, A. B. H. Novo Dicionário da Língua Portuguesa. 2. ed. Rio de Janeiro: Nova Fronteira. 1986.

FIGUEIREDO, F. F. Courseware "estudando porcentagem". In: ENCONTRO NACIONAL DE EDUCAÇÃO MATEMÁTICA, 11., 2013, Curitiba. Anais... Curitiba: SBEM, 2013. p. 1-5.

FONSECA, M. C. F. R. Por que ensinar matemática. Presença Pedagógica, Belo Horizonte, v.1, n.6, p.46-54, mar./abr. 1995.

FREIRE, P. Pedagogia da Autonomia: saberes necessários à prática educativa. 36. ed. São Paulo: Paz e Terra, 2011.

LIMA, I. G; SAUER, L. Z. Razão e emoção em ambientes de aprendizagem: em busca da unidade. In: VALENTINNI, C. B.; SOARES, E. M. S. (org.). Aprendizagem em ambientes virtuais: compartilhando ideias e construindo cenários. 2. ed. Caxias do Sul: Educs, 2005. p. 68-78.

JUNIOR, O. P. JOUCOSKI, E. O ensino da matemática financeira: relato de uma experiência de aprendizagem. Paraná/ PDE, 2008.

KLIEMANN, G. L.; SILVA, P. F. da; DULLIUS, M. M. Relevância da Matemática Financeira no Ensino Fundamental. Revista destaques acadêmicos, Lajeado, ano 3, n. 4, p. 95-104, 2011.

KISTEMANN JR., M. A. Sobre a produção de significados e a tomada de decisão de indivíduos-consumidores. 2011. Tese (Doutorado em Educação Matemática) - Instituto de Geociências de Ciências Exatas, Universidade Estadual Paulista, Rio Claro, 2011.

LUZ, L. H.; BAYER, A. Matemática Financeira na Educação Básica. In: CONGRESSO INTERNACIONAL DE ENSINO DA MATEMÁTICA, 6., 2013, Canoas-RS. Anais... Canoas: ULBRA, 2013. p. 1-13.

MENDES, Iran Abreu. Matemática e investigação em sala de aula: tecendo redes cognitivas na aprendizagem. 2. ed. São Paulo: Livraria da Física, 2009.

MIRANDA, L. A. N.; PHILIPPSEN, A. S. A importância da Matemática Financeira no cotidiano e na construção da cidadania. Cadernos PDE, Paraná, v. 1, n. 1, p. 1-17, 2014.

MOREIRA, F. M. C. Cenários para investigação como ambiente de aprendizagem no contexto da matemática financeira. 2014. Dissertação (Mestrado Profissional em Educação Matemática) - Instituto de e Ciências Exatas e Biológicas, Universidade Federal de Ouro Preto, Ouro Preto, 2014. 
DOI: http://dx.doi.org/10.33238/ReBECEM.2019.v.3.n.2.22637

PELICIOLI, A. F. A relevância da Educação Financeira na formação de jovens. 2011. Dissertação (Mestrado em Educação em Ciências e Matemática) - Faculdade de Física, Pontifícia Universidade Católica do Rio Grande do Sul, Porto Alegre, 2011.

PESSOA, C. A. dos S.; MUNIZ JR, I.; KISTEMANN JR, M. A. Cenários sobre educação financeira escolar: entrelaçamentos entre a pesquisa, o currículo e a sala de aula de matemática. EM TEIA - Revista de Educação Matemática e Tecnológica Iberoamericana, [S.I.], v. 9, n. 1, p. 1-28. 2018.

RESENDE, A. F. de. A Educação Financeira na Educação de Jovens e Adultos: uma leitura da produção de significados financeiro-econômicos de dois indivíduos-consumidores. 2013. Dissertação (Mestrado Profissional em Educação Matemática) - Instituto de Ciências Exatas, Universidade Federal de Juiz de Fora, Juiz de Fora, 2013.

SANTOS, L. T. B. dos. PESSOA, C. A. dos S. Educação financeira na perspectiva da educação matemática crítica: uma reflexão teórica à luz dos ambientes de aprendizagem de Ole Skovsmose. BoEM, Joinville, v. 4. n. 7, p. 23-45, ago./dez. 2016.

SILVA, A. M, POWELL, A. B. Um programa de Educação Financeira para a Matemática Escolar da Educação Básica. In: ENCONTRO NACIONAL DE EDUCAÇÃO MATEMÁTICA, 11., 2013, Curitiba. Anais... Curitiba: SBEM, 2013. p. 1-17.

SKOVSMOSE, O. Cenários para investigação. Bolema, Rio Claro, v. 13, n. 14, p. 66-91, 2000.

SKOVSMOSE, O. Educação Matemática Crítica: A questão da democracia. Tradução de Abigail Lins e Jussara de Loiola Araújo. 5. ed. Campinas: Papirus, 2001.

TEIXEIRA, James. Um estudo diagnóstico sobre a percepção da relação entre educação financeira e Matemática Financeira. 2015. Tese (Doutorado em Educação) - Pontifícia Universidade Católica de São Paulo, São Paulo, 2015.

THEODORO, F. R, F. Centro estadual de educação tecnológica paula souza mestrado em tecnologia: Uma análise diagnóstico-positivo. 2011. Dissertação (Mestrado em Tecnologia) Centro Educacional de Educação Tecnológica Paula Souza, São Paulo, 2011.

UTPADEL, S. C. A percepção do comportamento consumista em adolescentes de diferentes níveis socioeconômicos. Trabalho de Conclusão de Curso (Bacharel em Psicologia) - Centro de Educação de Ciênciass da Saúde, Universidade do Vale do Itajaí, Itajaí, 2007.

Recebido em: 17 de junho de 2019.

Aceito em: 09 de agosto de 2019. 